University of Nebraska - Lincoln

DigitalCommons@University of Nebraska - Lincoln

2006

Intra-seasonal NDVI change projections in semi-arid Africa

Chris C. Funk

University of California - Berkeley, chris@geog.ucsb.edu

Molly E. Brown

NASA Goddard Space Flight Center Biospheric Sciences Branch, molly.brown@nasa.gov

Follow this and additional works at: https://digitalcommons.unl.edu/nasapub

Funk, Chris C. and Brown, Molly E., "Intra-seasonal NDVI change projections in semi-arid Africa" (2006). NASA Publications. 130.

https://digitalcommons.unl.edu/nasapub/130

This Article is brought to you for free and open access by the National Aeronautics and Space Administration at DigitalCommons@University of Nebraska - Lincoln. It has been accepted for inclusion in NASA Publications by an authorized administrator of DigitalCommons@University of Nebraska - Lincoln. 


\title{
Intra-seasonal NDVI change projections in semi-arid Africa
}

\author{
Chris C. Funk $^{\text {a,* }}$, Molly E. Brown ${ }^{b}$ \\ ${ }^{a}$ Climate Hazard Group, Geography Department, University of California, Santa Barbara, CA, United States \\ ${ }^{\mathrm{b}}$ Science Systems and Applications, NASA Goddard Space Flight Center, Greenbelt, MD, United States
}

Received 26 August 2005; received in revised form 19 December 2005; accepted 21 December 2005

\begin{abstract}
Early warning systems (EWS) tend to focus on the identification of slow onset disasters such famine and epidemic disease. Since hazardous environmental conditions often precede disastrous outcomes by many months, effective monitoring via satellite and in situ observations can successfully guide mitigation activities. Accurate short term forecasts of NDVI could increase lead times, making early warning earlier. This paper presents a simple empirical model for making 1 to 4 month NDVI projections. These statistical projections are based on parameterized satellite rainfall estimates (RFE) and relative humidity demand (RHD). A quasi-global, 1 month ahead, $1^{\circ}$ study demonstrates reasonable accuracies in many semi-arid regions. In Africa, a $0.1^{\circ}$ cross-validated skill assessment quantifies the technique's applicability at 1 to 4 month forecast intervals. These results suggest that useful projections can be made over many semi-arid, food insecure regions of Africa, with plausible extensions to drought prone areas of Asia, Australia and South America.

(C) 2006 Elsevier Inc. All rights reserved.
\end{abstract}

Keywords: Early warning; Africa; Food security; NDVI; Precipitation; Rainfall; Malaria; Rift valley fever; Pastoral livelihoods

\section{Introduction}

In areas with limited in situ data, NDVI and satellite rainfall estimates are routinely used to identify areas prone to drought related crop failure and poor pasture conditions (FEWS, 2000; Field, 1991; Hutchinson, 1998), malaria (Hay et al., 1998) and Rift Valley Fever (RVF) (Linthicum et al., 1999), and damaging pests such as locusts (Hielkema et al., 1986; Tucker et al., 1985). These satellite observations are routinely used by development organizations working in semi-arid regions where agriculture and pastoralism are the primary livelihood strategy (Maxwell, 1996; Watts, 1987; Webb \& Rogers, 2003). By monitoring environmental and social conditions, governments and international, national and local organizations have been able to respond rapidly to food crises. This paper describes a statistical approach for making intra-seasonal projections of vegetation change, thereby providing the potential for earlier early warning of these events.

\footnotetext{
* Corresponding author. Tel.: +1 8058938322 .

E-mail address: chris@geog.ucsb.edu (C.C. Funk).
}

The enhanced integration of remotely sensed vegetation and precipitation products has an immediate and interested audience, with the ability to inform policy and emergency response agencies and governments. One way of leveraging the substantial human investment in the environmental monitoring of vegetation (Eklundh, 1996; Hielkema et al., 1986; Kawabata et al., 2001; Prince \& Justice, 1991; Tucker et al., 1986), precipitation (Adler et al., 1994; Arkin et al., 1994; Huffman et al., 1995, 1997; Love et al., 2004; Xie \& Arkin, 1996) and atmospheric conditions (Kalnay et al., 1996) is to use observed environmental conditions to make predictions of future land surface properties.

Many studies have described the dependency of vegetation on variations of rainfall and temperature (Davenport \& Nicholson, 1993; Lotsch et al., 2003a; Nicholson et al., 1997; Richard \& Poccard, 1998; Tucker \& Nicholson, 1999). The Normalized Difference Vegetation Index or NDVI from NOAA's Advanced Very High Resolution Radiometer (AVHRR) instrument has been used to assess climate in semi-arid zones where rainfall records are scarce or difficult to obtain in a timely fashion (Davenport \& Nicholson, 1993; Zhou et al., 2003). A month lead-time can prove critical in 
minimizing the impacts of these hazards. This paper demonstrates one way in which the lagged relationship between rainfall and NDVI can be used to estimate vegetation response to current conditions, helping to make early warning systems earlier. We refer to these statistical estimates of NDVI change as 'projections' to differentiate them from climate-based forecasts of NDVI (Anyamba et al., 2002; Verdin et al., 1999). The approach described here is distinct from and compatible with climate-modeling approaches. Our focus is on the direct use satellite-observed precipitation as a basis for forecasting NDVI.

\section{Data}

The following sections describe the datasets that were used in the model: $1^{\circ}$ monthly precipitation fields from the Global Precipitation Climatology Project (GPCP), $0.1^{\circ}$ monthly precipitation fields from NOAA's Climate Prediction Center, relative humidity fields from the National Climatic Diagnostics Center's reanalysis, and $1^{\circ}$ and $0.1^{\circ}$ monthly AVHRR NDVI data from NASA's Global Inventory Monitoring and Modeling Systems group (GIMMS).

\subsection{Global and operational contexts}

In this study, the data were used at two spatial resolutions: $1 \%$ quasi-global $\left(50 \mathrm{~N} / \mathrm{S}, 180^{\circ} \mathrm{W}\right.$ to $\left.180^{\circ} \mathrm{E}\right)$ and $8 \mathrm{~km}$ African $\left(40^{\circ}\right.$ $\mathrm{N} / \mathrm{S}, 20^{\circ} \mathrm{W}$ to $55^{\circ} \mathrm{E}$ ) data re-projected to the Plate Carree or geographic $0.1^{\circ}$ resolution. The $1^{\circ}$ data provides global validation with low signal-to-noise ratios for the inputs. The $0.1^{\circ}$ scale recreates the operational context used in weekly monitoring by FEWS NET.

\subsection{Precipitation data}

This analysis used two sources of precipitation: the global GPCP Version 2 Combined Precipitation Dataset (Huffman et al., 1995, 1997) and the African 0.1 ${ }^{\circ}$ Rainfall Estimate or RFE climatology. The GPCP is a $2.5^{\circ}$ merged analysis incorporating precipitation estimates from low-orbit-satellite infrared data and rain gauge observations. This study used $1^{\circ}$ monthly gridded area-mean rainfall totals and error estimates over the January 1979 to January 2001 period (GPCP, 2001). For Africa, NOAA's Climate Prediction Center's African RFE Climatology (ARC, Love et al., 2004) provides a unique resource for studying rainfall variability. The CPC's ARC dataset is similar in spirit to climate reanalysis projects. A fixed algorithm, the RFE 2.0 method (Xie \& Arkin, 1996; Xie et al., 2002) is applied consistently to a long homogeneous set of $0.1^{\circ}$ three-hourly Meteosat infrared and Global Telecommunications System rain gauge data. While the ARC estimates lack additional satellite inputs used in the operational RFE 2.0 estimates, it has much longer period of record (1995-present as opposed to 2001-present). The ARC data is used operationally by USAID's Famine Early Warning System, and is available for download from www.fews.net.

\subsection{Relative humidity data}

This study has used surface relative humidity (the 0.995 sigma level) fields from the National Centers for Environmental Prediction (NCEP)/National Center for Atmospheric Research (NCAR) reanalysis. These fields are at a $2.5^{\circ}$ resolution and are available from January 1948 to present. Atmospheric fields in the reanalysis are derived from solutions to the primitive equations for vorticity, divergence, virtual temperature, logarithm of surface pressure and specific humidity on a T62 spectral grid with 28 unequally spaced sigma levels (Kanamitsu, 1989; Kanamitsu et al., 1991; Sela, 1980). The data were resampled to a $1.0^{\circ}$ and a $0.1^{\circ}$ resolution using cubic convolution.

Moisture related parameters in the reanalysis are considered much less reliable than temperature, pressure or wind fields, which are constrained by observations. Despite the approximate nature of these fields, both our previous efforts modeling rainfall in Africa (Funk \& Michaelsen, 2004; Funk et al., 2003b) and the ongoing use of statistically corrected climate forecast models (Landman \& Goddard, 2002) have demonstrated that climate models can provide useful information regarding atmospheric moisture conditions. 'True' relative humidity varies more smoothly in space and time than rainfall, making the use of reanalysis based on relative humidity plausible.

\subsection{NDVI data}

The AVHRR-based NDVI time series is from the NASA NDVIe dataset produced by the NASA Global Inventory Monitoring and Modeling Systems (GIMMS) group. The NDVIe is based on a pre-existing dataset produced by members of the GIMMS group at the Laboratory for Terrestrial Physics in the late 1990s. The NDVI was mapped from an in-house library of AVHRR level 1B data (Tucker et al., 2005). Corrections to the dataset include volcanic aerosol correction in 82-84 and 91-93, cloud screening, desert calibration, and a solar zenith angle correction (Los, 1998; Mahoney et al., 2001; Vermote et al., 1997; Vermote \& Kaufman, 1995).

The solar zenith angle correction was applied during postprocessing to remove non-vegetative artifacts due to orbital drift and changes in sun-target-sensor geometry (Pinzon, 2002; Pinzon et al., 2005). A kriging interpolation removes noise and attenuates the effect of cloudy and missing pixels. The resulting data has a high signal-to-noise ratio and has a comparable range to that of MODIS and SPOT-Vegetation (NDVI values of 0.05 to 0.95 ) (Tucker et al., 2005). This dataset has been used in several studies in the past few years (Brown et al., in press; Lotsch et al., 2003b; Zeng et al., 1999).

It should be noted that the vegetation, and hence NDVI, will tend to vary on much shorter spatial scales than relative humidity and rainfall estimates. The modeling approach described in the next section links NDVI variations with combinations of NDVI, precipitation and relative humidity, thus using the NDVI to 'sharpen' the landscape response to smooth rainfall and humidity fields. 


\section{Methods}

\subsection{Modeling NDVI change as a function of NDVI state and environmental forcing}

This model seeks reasonable predictions of NDVI values over relatively short time scales (1 to 4 months), based on environmental forcing factors. The authors work closely with FEWS NET, a food security early warning decision support system, thus our objective is to create a simple and effective means of quantifying the future effects of observed environmental conditions. The framework described here uses observed precipitation, relative humidity and NDVI values to project NDVI change. Forecast precipitation and relative humidity fields could easily be incorporated, using information from dynamic, statistical or dynamic-statistical climate models. Extensions including more environmental parameters would likely improve performance, especially in mid-latitude climes. The model focuses on month-to-month NDVI change. These values can then be used to estimate future values of NDVI. We begin with a description of a simple 1 month-ahead implementation at quasi-global resolution, and then develop the more complete version that incorporates lags from 1 to 5 months for Africa. We find that the combination of NDVI state, precipitation and relative humidity information can be used to forecast NDVI in semi-arid Africa.

The NDVI change at time $t$ at some location $\left(\Delta N_{t}=N_{t}-N_{t-1}\right)$ can be approximated by NDVI growth and loss terms. Since vegetation is mostly water, this can be grossly considered as a balance between precipitation/soil moisture uptake and a transpiration related loss component. NDVI state is important. The growth associated with a given precipitation value is greater when the NDVI is far below its maximum value, and zero when this NDVI value is achieved. Similarly the NDVI loss term associated with low relativity humidity values will be greatest when the NDVI value is highest, and zero when the NDVI value is at its historic minimum.

This approach is guided by the broad characteristics of rain and the resulting green vegetation. Early in the rainy season, precipitation tends to produce rapid green-up and water absorption. Late in the season, increased leaf area can produce higher rates of evapotranspiration and brown-down or vegetation senescence. Constrained NDVI growth estimates are derived from the $\log$ of monthly precipitation values. Constrained NDVI loss estimates are based on a transform of relative humidity $(100-\mathrm{RH})$. We refer to this latter term as relative humidity demand (RHD).

The bivariate 1 month-ahead form of the model is

$$
\begin{aligned}
\Delta \hat{N}_{t}= & b_{1}\left(N_{\max }-N_{t-1}\right) \ln \left(1+P_{t-1}\right) \\
& -b_{2}\left(N_{t-1}-N_{\min }\right)\left(100-\mathrm{RH}_{t-1}\right)
\end{aligned}
$$

where $\Delta \hat{N}_{t}$ is the change in NDVI at time $t-1$ and $t, b_{1}$ and $b_{2}$ are least-squares-fit parameters, $N_{\max }$ and $N_{\min }$ are historic maximum and minimum observed NDVI at a given location, $N_{t}$, $P_{t}$ and $\mathrm{RH}_{t}$ are the observed monthly NDVI, precipitation and relative humidity at the time the forecast is made.
Note that this modeling approach automatically limits the range of the NDVI to the historically observed extremes, and provides an unsophisticated water-balance approach to modeling NDVI response. When NDVI values are low, leaf area and soil moisture values are typically low, enabling the plant/soil system to capture and use a large fraction of the available water. When NDVI values are high, soil moisture and vegetation cover are typically near their maximum values, and a larger fraction of rainfall will be lost from the soil/vegetation system through runoff and evapotranspiration from the land and plant surfaces. When NDVI values are low, both plant leaf area and stomatal conductance are low, reducing moisture loss to atmosphere.

\subsection{The full NDVI projection model}

Many studies have shown links between NDVI and rainfall at 2 months, 3 months or even greater lags (Ji \& Peters, 2003; Kerr et al., 1989; Piao et al., 2003; Potter et al., 1999). We extend the bivariate model, therefore, to include lags between 1 and 5 months. This can be expressed in matrix notation as

$\Delta \hat{N}_{t}=b^{T} F$

$F_{1 \ldots 5}=\left(N_{\max }-N_{t-0 \ldots 4}\right) \ln \left(1+P_{t-0 \ldots 4}\right)$

$F_{6 \ldots 10}=\left(N_{t-0.4}-N_{\min }\right)\left(100+\mathrm{RH}_{t-0 \ldots 4}\right)$

where $b$ is a vector of least-squared-error derived weights, and $F$ is a vector of growth and loss terms associated with monthly lags 0 through 4 . Observant readers will note that for a 1 month ahead forecast model, the 0 lag values will not be available, since the index $t=0$ denotes a month in the future. This limitation is overcome by substituting climatological averages for $N$, RH and $P$ when future values are required. This process allows us to create estimates for 1 to 4 months ahead forecast scenarios. The 1-month forecast uses 1 month of climatic average data, and 4 months of past rainfall and RH values. The 4-month model uses 1 month of observed data and 4 months of climatic average data.

An advantage of this modeling approach is the simplicity with which climate forecast values could be incorporated. These values can replace the climatic averages with estimates derived from any reasonable climate forecast. This application remains to be explored in future work.

\subsection{Forecast validation — definition of the cross-validated skill metric}

It is important to note that Eqs. (1) and (2) convolve the seasonal cycle and anomalous conditions into a single estimate of NDVI change. We assess the model therefore using leaveone-out cross-validated skill statistics based on NDVI anomalies (Michaelsen, 1987). Leave-one-out cross-validation is an iterative procedure in which one sample is held out on each run, and the rest of the sample data are used to predict the value of the excluded datum. The variance of these errors is accumulated and used to estimate the ratio variance of the NDVI anomalies explained $\left(R^{2}\right)$. 


\section{Analysis of model results}

This section presents the results of the model and evaluates its effectiveness. Section 4.1 quantifies the cross-validated forecast skill associated with the 5-month NDVI projections (Eq. (2)) at 1- to 4-month forecast lags in Africa. Section 4.2 applies the simple month ahead model (Eq. (1)) to a quasiglobal grid, identifying other regions in which the model might be applied successfully with few modifications.

\subsection{Cross-validated skill assessment for Africa}

Fig. 1 shows results for the cross-validated projections based on the $0.1^{\circ}$ NASA NDVIe and CPC ARC datasets. These results are based on the full NDVI projection model (Eq. (2)). These skill values are based on the monthly NDVI anomalies and thus have the seasonal cycle removed. Panels A and B show the 2-month and 4-month forecast skills. These skills are high over many parts of semi-arid Africa. These areas, which tend to be poorly explained by the seasonal cycle alone, correspond to portions of Eastern Africa (especially Kenya, Somalia and Ethiopia), along the northern Sahel, and in drought prone regions of southern Africa stretching from southern Mozambique to the northwest corner of Namibia. While these areas are relatively small in spatial extent, they contain important food security hot spots.

\subsection{The near-global NDVI model analysis}

Fig. 2 shows the shows the simple 1-month ahead forecast model multiple $r$ on a quasi-global scale. The simple model works well across large stretches of the semiarid and semi-humid sub-tropics within $\pm 40^{\circ} \mathrm{N} / \mathrm{S}$. Large areas of Mexico, portions the Llanos and Guiana highlands in Venezuela, large areas of southeastern Brazil and Paraguay and the dry coastal regions of equatorial and sub-tropical areas of eastern South America are modeled well. Most of sub-tropical Africa is also captured fairly well $(r>0.6)$, with notable exceptions being the Zaire basin and the Kalahari and Somali deserts. Most of India and portions Tibetan plateau have high correlations as does the Irrwaddy basin in Myanmar. Northern Australia NDVI change also appears to be highly predictable at a 1-month lag. These

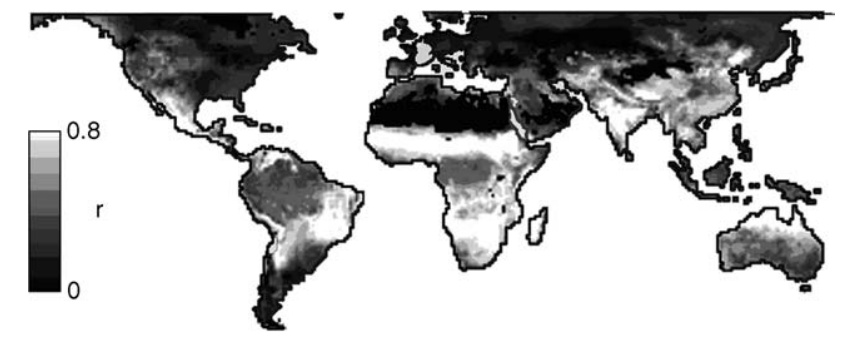

Fig. 2. Regression multiple $r$ of simple model (Eq. (1)) applied quasi-globally.

regions seem likely candidates for operational NDVI projection applications.

\section{Model case studies}

This section illustrates the utility of the model in an NDVIfood security application in Ethiopia and an evaluation of the NDVI projections for the early identification of Rift Valley Fever conditions the Greater Horn.

\subsection{Ethiopia food security application}

Fig. 3 combines two sets of information: average May-June NDVI from 1981 to 2005 (vertical columns), and FEWS NET estimates of millions of people needing food aid (black line) from 1996 to 2004. Previous analyses have suggested a surprising dependence of Ethiopian crop production and food needs to Belg (March-April-May) rains (Funk et al., 2003a). Recent reductions in these Belg rains have been observed in precipitation time series, and may be related to increasing sea surface temperatures in the Indian Ocean (Funk et al., 2005; Verdin et al., 2005). This recent dryness is also apparent in the May-June NDVI shown in Fig. 3.

The May-June NDVI explains $72 \%$ of the annual variance in food aid needs. Bivariate regression-based food aid projections are plotted as a light gray line. Also shown are food security forecasts based on projected NDVI (black bars in Fig. 3). These values use observed $\mathrm{RH}$ and $\mathrm{CPC}$ precipitation fields to predict the May-June NDVI growth. These growth estimates may be combined with observed April NDVI and then expressed as an indicator (68\% variance explained) of food aid needs based on production shortfall. Given that crop

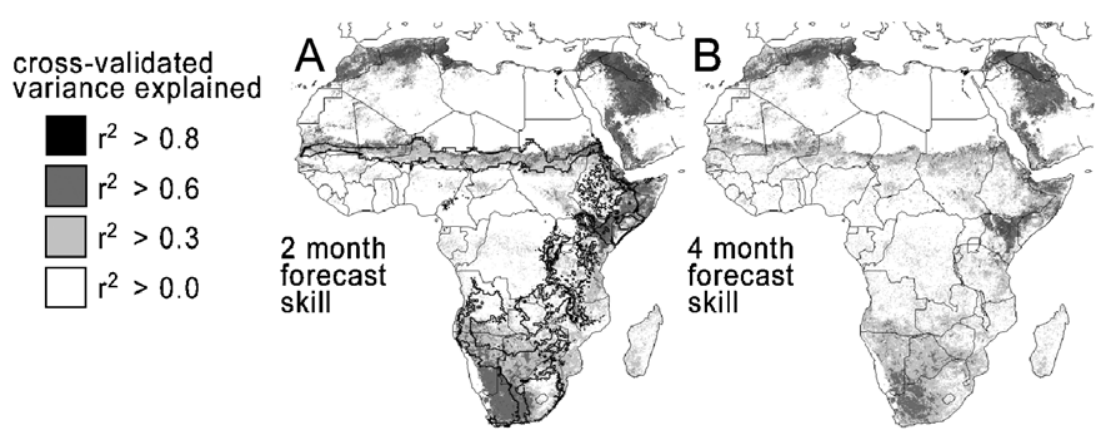

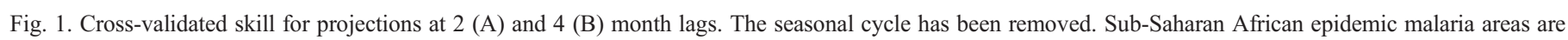
shown with heavy black lines. Malaria areas were provided by the USGS FEWS NET program. 


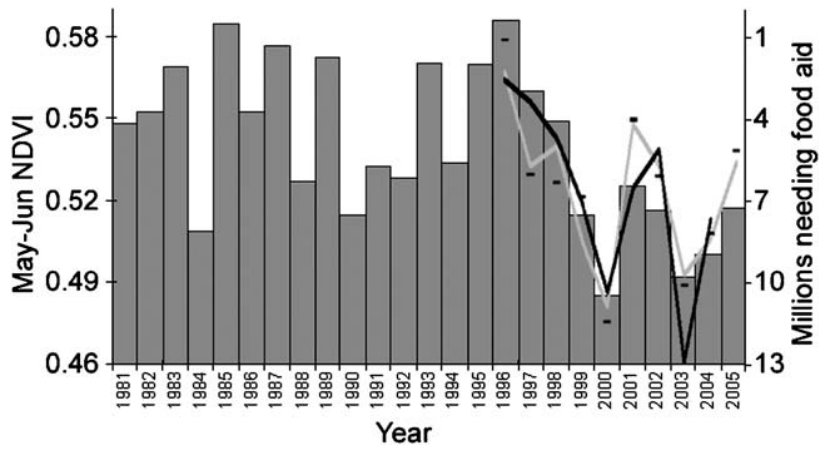

Fig. 3. Ethiopian May-June NDVI and millions need food aid, observed (black lines), predicted via observed NDVI (gray line), and predicted via projected NDVI (black dashes).

assessments are typically carried out in October, NDVI can be used to provide earlier early warning. Observed May-June NDVI leads crop assessment information by approximately 3 months. NDVI projections can reasonable extend this lead-time by another month or two. Many factors convolve to create food insecurity, but NDVI and NDVI projections can provide early warning of environmental shocks.

\subsection{NDVI projections of Rift Valley Fever conditions}

In 1997/1998 an extensive outbreak of Rift Valley Fever (RVF) occurred in the Greater Horn of Africa, with more than 27,500 cases occurring in the Garissa district of Northeastern Kenya (Woods et al., 2002) costing the region more than $\$ 100$ million, and endangering fragile pastoral livelihoods. RVF is a vector-borne disease, which has been shown to be linked to above normal NDVI (Linthicum et al., 1999). GCM-based NDVI forecasts may be useful future indicators of RVF risk (Thomson et al., 2003). NDVI projections averaged over a large $\left(222,000 \mathrm{~km}^{2}\right)$ region of northeastern Kenya represent well the monthly variation of NDVI anomalies (Fig. 4). Note the timelag of the predictions - this is typical of auto-regressive models. The overall correlation between the 4-month forecasts and the observed NDVI anomalies has an $r^{2}$ value of 0.83 . The large positive excursion in the winter of 1997/1998 is captured effectively 4 months in advance, suggesting a good opportunity for preparedness and mitigation. Note, however, that the forecast value does under-estimate the maximum value. Future research may show that this tendency to under-estimate the extremes can be alleviated by using minimum and maximum NDVI values slightly beyond the historical range.

\section{Approach and limitations}

Consideration of linearized biomass functions used in the Sahel (Zeng et al., 1999), the semi-empirical conductance expressions (Sellers et al., 1997) used in sophisticated biological models led to the formulation described here. NDVI is well related to the past several months of rainfall in semi-arid regions (Nicholson et al., 1990; Richard \& Poccard, 1998) and NDVI maximum and minimum values are heavily constrained by environmental conditions and can therefore be assumed as stationary for short range forecasting applications. The model, as formulated, is only applicable to semi-arid and semi-humid regions of the tropics. Both Fig. 2 and previous research (Potter \& Brooks, 1998) suggest a transition between 'cold' and 'warm' regions at about $40^{\circ} \mathrm{N} / \mathrm{S}$. The semi-arid regions of Africa, Asia and North and South America all stand out in Fig. 2 as regions that are controlled by precipitation and humidity. In these regions NDVI is closely coupled to net primary productivity (NPP) and canopy structure (Tucker \& Sellers, 1986). The spatial distribution of regions phenologically limited by available water vapor (Jolly et al., 2005) corresponds well with regions showing strong correlations in Fig. 2. Alternately, areas with low correlations tend to be either not water limited (tropics) or limited by photoperiod and minimum temperature (mid-latitudes). Thus, in water limited regions precipitation is tightly coupled to inter-annual variability in ecosystem dynamics (Lotsch et al., 2003a; Trenberth, 1998), and therefore useful for predicting NDVI.

It is important to note that the model presented is diagnostic, not prognostic. It makes projections based on observed values for NDVI, precipitation and relative humidity. The observed state of NDVI is an important input, as are the NDVI minimum and maximum constraints. This appears reasonable from an early warning perspective, but the current formulation is not directly applicable to biogeophysical modeling applications. The assumption of stationarity in minimum and maximum NDVI is not strictly true. Changes in Max NDVI in Senegal, for example, have been related to changes in crop and rangeland use (Fuller, 1998), while positive trends in NDVI values in Tanzanian woodland and forest pixels have been related to changes in conservation policies (Pelkey et al., 2000). Since the model depends heavily on the NDVI, it will inherit known NDVI shortcomings. In humid areas the NDVI will tend to saturate, and in arid or semi-arid regions soil, surface moisture and aerosol signals may limit the accuracy of the observed
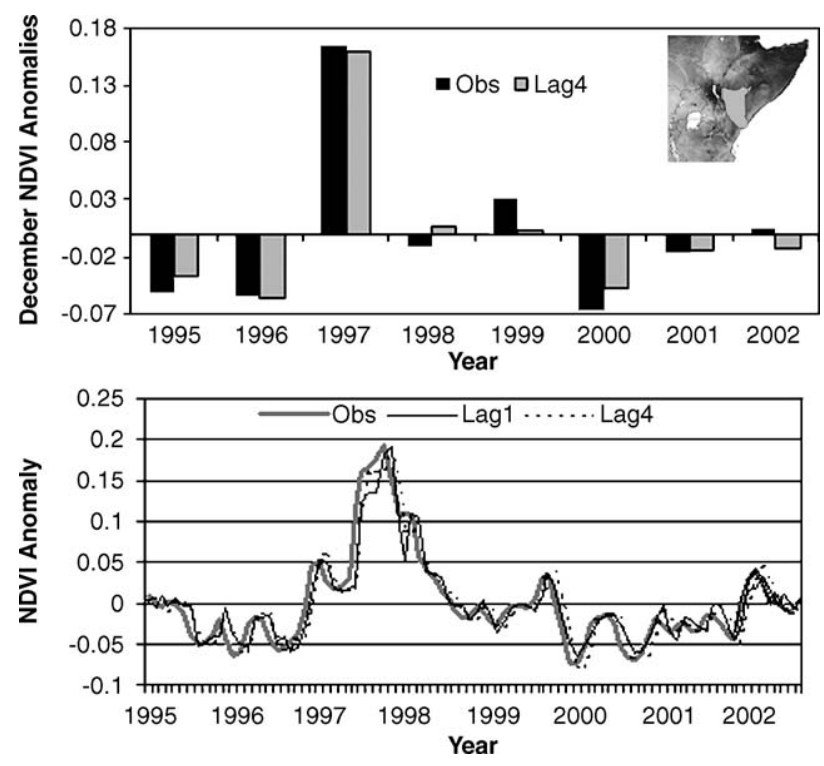

Fig. 4. Observed and projected NDVI anomalies for December (top) and all months (bottom) averaged over northeastern Kenya. 
NDVI. Decadal variability and climate change can also affect the stability of the maximum and minimum constraints.

\subsection{Potential model extensions}

The present formulation could be extended by adding additional environmental parameters, modeling the maximum and minimum NDVI values explicitly and better specifying the functional form of the transfer functions. Temperature and surface radiation terms are natural candidates for extensions, and the fairly large number of degrees of freedom $(240+$ in AVHRR time series) could support a modest increase in model complexity. Alternately, simple models could be applied to higher resolution, shorter period of record NDVI time series, or fit seasonally. Another obvious area of potential development could replace the climatological averages of precipitation and relative humidity used in Eq. (2) with forecast values. Further studies into the optimal fitting function (linear, log, etc.) between the RHD and precipitation terms could also yield modest improvements in forecast skill.

\subsection{Potential applications for pastoral, malaria and Rift Valley Fever monitoring in Africa}

As population pressure, climate change and land degradation place increasing pressure on fragile pastoral and agro-pastoral environments, the need to improve monitoring and early warning increases. The proposed model, or some close relative, could be implemented operationally to improve early warning systems. The spatial distribution of forecast skill (Fig. 1) seems applicable to pastoral applications. Positive rainfall and associated NDVI anomalies have been identified as a key risk indicator (Linthicum et al., 1999) for epizootic RVF and Malaria (Hay et al., 2003). These diseases in epidemic form tend to arise in semi-arid regions where the model performs well.

\section{Conclusion}

Because food insecurity typically results from a combination of climate events and societal vulnerabilities, crises almost always arise in areas with limited in situ data. Satellite information is thus the first line of defense for many of the world's millions of food insecure. Information on the progress of the growing season as measured by meteorological satellites combined with extensive social science and livelihood information provides actionable guidance and early warning of food security crises (Mathys, 2005). These assessments are often needed for deadlines imposed by the budgetary cycle of large international donor organizations such as the US Agency for International Development or the UN World Food Program. Early assessments of large potential crop losses are key to finding the funds and to sending local assessment teams to trouble spots and for arranging for early and adequate shipments of food aid to regions in need. These practical timing and budgetary considerations are the impetus of this research and define the user community for new products.
The study results presented here are quite promising, suggesting that useful projections can be made over most semi-arid regions of Africa, with potential extensions to drought prone areas of Asia, Australia and South America. These projections will be integrated into existing early warning systems, allowing for the advance identification of climate impacts affecting agricultural and pastoral regions. As monitoring activities expand into new regions, the extended model may become an important tool for protecting the lives and livelihoods of agricultural communities in semi-arid zones throughout the world.

\section{Acknowledgements}

We would like to thank the editor, Marvin Bauer, and two anonymous reviewers for thoughtful comments resulting in a much improved manuscript. Chip Stem of the African Union Interafrican Bureau for Animal Research and Maxx Dilley of the International Research Institute for Climate provided the original motivation for this research by bringing Rift Valley Fever to our attention. Early collaboration with James Verdin and Eric Wood of the USGS International Program demonstrated the strong climatic controls of NDVI in semi-arid Africa. The African Rainfall Climatology produced by Tim Love at the Climate Prediction Center was critical, as were the NDVI timeseries distributed by the NASA GIMMS program. Funding for this work was provided by the USAID Famine Early Warning System Network and an EPA STAR fellowship.

\section{References}

Adler, R. F., Huffman, G. J., \& Keehn, P. R. (1994). Global rain estimates from microwave-adjusted geosynchronous IR data. Remote Sensing Reviews, 11, $125-152$.

Anyamba, A., Linthicum, K. J., Mahoney, R., Tucker, C. J., \& Kelley, P. W. (2002). Mapping potential risk of Rift Valley Fever outbreaks in African savannas using vegetation time series data. Photogrammetric Engineering and Remote Sensing, 68, 137-145.

Arkin, P. A., Joyce, R., \& Janowiak, J. E. (1994). IR techniques: GOES precipitation index. Remote Sensing Reviews, 11, 107-124.

Brown, M. E., Pinzon, J. E., Didan, K., Morisette, J. T., \& Tucker, C. J. (in press). Evaluation of the consistency of long-term NDVI time series derived from AVHRR, SPOT-Vegetation, SeaWIFS, MODIS and LandSAT ETM+. IEEE Transactions on Geoscience and Remote Sensing.

Davenport, M. L., \& Nicholson, S. E. (1993). On the relation between rainfall and the normalized difference vegetation index for diverse vegetation types in East Africa. International Journal of Remote Sensing, 14, 2369-2389.

Eklundh, L. (1996). AVHRR NDVI for monitoring and mapping vegetation and drought in East Africa environments. PhD, Lund University Press.

FEWS (2000). Framework for food crisis contingency planning and response. Arlington, VA: FEWS-ARD.

Field, J. O. (1991). Beyond relief: Toward improved management of famine. In H. G. Bohle, T. Cannon, G. I. Hugo, \& F. N. Ibrahim (Eds.), Famine and food security in Africa and Asia: Indigenous response and external intervention to avoid hunger (pp. 151-166). Bayreuth, Germany: Verlag.

Fuller, D. O. (1998). Trends in NDVI time series and their relation to rangeland and crop production in Senegal. International Journal of Remote Sensing, 19, 2013-2018.

Funk, C., Asfaw, A., Steffen, P., Senay, G., Rowland, J., \& Verdin, J. (2003a). Estimating Meher crop production using rainfall in the 'Long Cycle' region of Ethiopia. Santa Barbara, CA: University of California and USGS EROS Data Center. 
Funk, C., \& Michaelsen, J. (2004). A simplified diagnostic model of orographic rainfall for enhancing satellite-based rainfall estimates in data-poor regions. Journal of Applied Meteorology, 43, 1366-1378.

Funk, C., Michaelsen, J., Verdin, J., Artan, G., Husak, G., Senay, G., et al. (2003b). The collaborative historical African rainfall model: Description and evaluation. International Journal of Climatology, 23, 47-66.

Funk, C., Senay, G., Asfaw, A., Verdin, J., Rowland, J., Michaelsen, J., et al. (2005). Recent Drought Tendencies in Ethiopia and equatorial-subtropical eastern Africa, FEWSNET Special Report, August 2, 2005.

GPCP (2001). GPCP global combined precipitation data. Greenbelt, MD: NASA Goddard Space Flight Center.

Hay, S. I., Snow, R. W., \& Rogers, D. J. (1998). From predicting mosquito habitat to malaria seasons using remotely sensed data: Practice, problems and perspectives. Parasitology Today, 14, 306-313.

Hay, S. I., Were, E. C., Renshaw, M., Noor, A. M., Ochola, S. A., Olusanmi, I., et al. (2003). Forecasting, warning, and detection of malaria epidemics: A case study. The Lancet, 361, 1705-1706.

Hielkema, J. U., Prince, S. D., \& Astle, W. L. (1986). Rainfall and vegetation monitoring in the savanna zone of the Sudan using the NOAA AVHRR. International Journal of Remote Sensing, 7, 1499-1513.

Huffman, G. J., Adler, R. F., Arkin, P. A., Chang, A., Ferraro, R., Gruber, A., et al. (1997). The Global Precipitation Climatology Project, (GPCP) combined precipitation data set. Bulletin of the American Meteorological Society, 78, $5-20$.

Huffman, G. J., Adler, R. F., Rudolf, B., Schneider, U., \& Keehn, P. R. (1995). Global precipitation estimates based on a technique for combining satellitebased estimates, rain gauge analysis, and NWP model precipitation information. Journal of Climate, 8, 1284-1295.

Hutchinson, C. F. (1998). Social science and remote sensing in famine early warning. In D. Liverman, E. F. Moran, R. R. Rindfuss, \& P. C. Stern (Eds.), People and pixels: Linking remote sensing and social science (pp. 189-196). Washington, DC: National Academy Press.

Ji, L., \& Peters, A. J. (2003). Assessing vegetation response to drought in the northern Great Plains using vegetation and drought indices. Remote Sensing of Environment, 87, 85-98.

Jolly, W. M., Nemani, R., \& Running, S. W. (2005). A generalized, bioclimatic index to predict foliar phenology in response to climate. Global Change Biology, 11, 619-632.

Kalnay, E., Kanamitsu, M., Kistler, R., Collins, W., Deaven, D., Gandin, L., et al. (1996). The NCEP/NCAR 40-year reanalysis project. Bulletin of the American Meteorological Society, 77, 437-471.

Kanamitsu, M. (1989). Description of the NMC global data assimilation and forecast system. Weather Forecast, 4, 335-342.

Kanamitsu, M., Albert, J. C., Campana, K. A., Caplan, P. M., Deaven, D. G., Iredell, M., et al. (1991). Recent changes implemented into the global forecast system at NMC. Weather Forecast, 6, 425-435.

Kawabata, A., Ichii, K., \& Yamaguchi, Y. (2001). Global monitoring of interannual changes in vegetation activities using NDVI and its relationships to temperature and precipitation. International Journal of Remote Sensing, $22,1377-1382$.

Kerr, Y. H., Imbernon, J., Dedieu, G., Hautecoeur, O., Lagouarde, J. P., \& Seguin, B. (1989). NOAA AVHRR and its uses for rainfall and evapotranspiration monitoring. International Journal of Remote Sensing, 10, 847-854.

Landman, W. A., \& Goddard, L. (2002). Statistical recalibration of GCM forecasts over southern Africa using model output statistics. Journal of Climate, 15, 2038-2055.

Linthicum, K. J., Anyamba, A., Tucker, C. J., Kelley, P. W., Myers, M. F., \& Peters, C. J. (1999). Climate and satellite indicators to forecast rift valley fever epidemics in Kenya. Science, 285, 397-400.

Los, S. O. (1998). Estimation of the ratio of sensor degradation between NOAA AVHRR channels 1 and 2 from monthly NDVI composites. IEEE Transactions on Geoscience and Remote Sensing, 36, 206-213.

Lotsch, A., Friedl, M. A., Anderson, B. T., \& Tucker, C. J. (2003). Coupled vegetation-precipitation variability observed from satellite and climate records. Geophysical Research Letters, 30.

Lotsch, A., Friedl, M. A., \& Pinzon, J. E. (2003). Spatio-temporal deconvolution of NDVI image sequences using independent component analysis. IEEE Transactions on Geoscience and Remote Sensing, 41, $2938-2942$

Love, T. B., Kumar, V., Xie, P., \& Thiaw, W. M. (2004). 20-year daily Africa precipitation climatology using satellite and gauge data (pp. 5.4-5.7). American Meteorological Society.

Mahoney, R., Tucker, C. J., Anyamba, A., Brown, M., Slayback, D., Los, S. O., et al. (2001). Global remote sensing of vegetation from space by the NASA, GSFC GIMMS group international workshop on global change (pp. 17-29). Sendai Kyodo Printing Co. Ltd., Tohoku University.

Mathys, E. (2005). FEWS NET's approach to livelihoods-based food security analysis. Washington, DC: FEWS NET USAID.

Maxwell, D. G. (1996). Measuring food insecurity: The frequency and severity of coping strategies. Food Policy, 21, 291-303.

Michaelsen, J. (1987). Cross-validation in statistical climate forecast models. Journal of Climate and Applied Meteorology, 26, 1589-1600.

Nicholson, S. E., Davenport, M. L., \& Malo, A. R. (1990). A comparison of the vegetation response to rainfall in the Sahel and East Africa, using normalized difference vegetative index from NOAA AVHRR. Climatic Change, 17, 209-241.

Nicholson, S. E., Kim, J., Ba, M. B., \& Lare, A. R. (1997). The mean surface water balance over Africa and its interannual Variability. Journal of Climate, 10, 2981-3002.

Pelkey, N. W., Stoner, C. J., \& Caro, T. M. (2000). Vegetation in Tanzania: Assessing long term trends and effects of protection using satellite imagery. Biological Conservation, 94, 297-309.

Piao, S. L., Fang, J. Y., Zhou, L. M., Guo, Q. H., Henderson, M., Ji, W., et al. (2003). Interannual variations of monthly and seasonal normalized difference vegetation index, (NDVI) in China from 1982 to 1999. Journal of Geophysical Research, [Atmospheres], 108.

Pinzon, J. (2002). Using HHT to successfully uncouple seasonal and interannual components in remotely sensed data SCI 2002 Conference Proceedings Jul. 14-18. Orlando, FL: SCI International.

Pinzon, J., Brown, M. E., \& Tucker, C. J. (2005). Satellite time series correction of orbital drift artifacts using empirical mode decomposition. In N. Huang (Ed.), Hilbert-Huang transform: Introduction and applications, $p$. Chapter 10, Part II. Applications.

Potter, C. S., \& Brooks, V. (1998). Global analysis of empirical relations between annual climate and seasonality of NDVI. International Journal of Remote Sensing, 19, 2921-2948.

Potter, C. S., Klooster, S., \& Brooks, V. (1999). Interannual variability in terrestrial net primary production: Exploration of trends and controls on regional to global scales. Ecosystems, 2, 36-48.

Prince, S. D., \& Justice, C. O. (1991). Coarse resolution remote sensing of the Sahelian environment: Editorial. International Journal of Remote Sensing, 12, 1137-1146.

Richard, Y., \& Poccard, I. (1998). A statistical study of NDVI sensitivity to seasonal and interannual rainfall variations in Southern Africa. International Journal of Remote Sensing, 19, 2907-2920.

Sela, J. G. (1980). Spectral modeling at the national meteorological center. Monthly Weather Review, 108, 1279-1291.

Sellers, P. J., Randall, D. A., Betts, A. K., Hall, F. G., Berry, J. A., Collatz, G. J., et al. (1997). Modeling the exchanges of energy, water and carbon between continents and the atmosphere. Science, 275.

Thomson, M., Indeje, M., Connor, S., Dilley, M., \& Ward, N. (2003). Malaria early warning in Kenya and seasonal climate forecasts. The Lancet, 362, 580.

Trenberth, K. E. (1998). Atmospheric moisture residence times and cycling: Implications for rainfall rates and climate change. Climatic Change, 39, 667-694.

Tucker, C. J., Justice, C. O., \& Prince, S. D. (1986). Monitoring the grasslands of the Sahel 1984-1985. International Journal of Remote Sensing, 7, $1571-1581$.

Tucker, C. J., \& Nicholson, S. E. (1999). Variations in the size of the Sahara Desert from 1980 to 1997. Ambio, 28, 587-591.

Tucker, C. J., Pinzon, J. E., Brown, M. E., Slayback, D., Pak, E. W., Mahoney, R., et al. (2005). An Extended AVHRR 8-km NDVI Data Set Compatible with MODIS and SPOT Vegetation NDVI Data. International Journal of Remote Sensing, 26, 4485-4498. 
Tucker, C. J., \& Sellers, P. J. (1986). Satellite remote sensing of primary production. International Journal of Remote Sensing, 7, 1395-1416.

Tucker, C. J., Vanpraet, C., Sharman, L., \& van Ittersum, M. J. (1985). Satellite remote sensing of total herbaceous biomass production in the Senegalese Sahel: 1980-1984. Remote Sensing of Environment, 17, 233-249.

Verdin, J., Funk, C., Klaver, R., \& Roberts, D. (1999). Exploring the correlation between Southern Africa NDVI and Pacific sea surface temperatures: Results for the 1998 maize growing season. International Journal of Remote Sensing, 20, 2117-2124.

Verdin, J., Funk, C., Senay, G., \& Choularton, R. (2005). Climate science and famine early warning. Philosophical Transactions of the Royal Meteorological Society, B, 360, 2155-2168.

Vermote, E., \& Kaufman, Y. J. (1995). Absolute calibration of AVHRR visible and near-infrared channels using ocean and cloud views. International Journal of Remote Sensing, 16, 2317-2340.

Vermote, E., El Saleous, N., Kaufman, R. K., \& Dutton, E. (1997). Data preprocessing: Stratospheric aerosol perturbing effect on the remote sensing of vegetation: Correction method for the composite NDVI after the Pinatubo eruption. Remote Sensing Reviews, 15, 7-21.

Watts, M. (1987). Drought, environment and food security: Some reflections on peasants, pastoralists and commoditization in Dryland West Africa. In M. H. Glantz (Ed.), Drought and hunger in Africa: Denying famine a future. Cambridge: Cambridge University Press.

Webb, P., \& Rogers, B. L. (2003). Addressing the 'In' in food insecurity. Washington, DC: USAID Office of Food for Peace.

Woods, C. W., Karpati, A. M., Grein, T., McCarthy, N., Gaturuku, P., Muchiri, E., et al. (2002). An outbreak of Rift Valley fever in northeastern Kenya, 1997-98. Emerging Infectious Diseases, 8, 138-144.
Xie, P., \& Arkin, P. A. (1996). Analysis of global monthly precipitation using gauge observations, satellite estimates, and numerical model prediction. Journal of Climate, 9, 840-858.

Xie, P., Yarosh, Y., Love, T., Janowiak, J., \& Arkin, P. A. (2002). A real-time daily precipitation analysis over South Asia 16th conference on hydrology. Orlando, FL: American Meteorological Society.

Zeng, N., Neelin, J. D., \& Lau, W. K. -M. (1999). Enhancement of interdecadal climate variability in the Sahel by vegetation interaction. Science, 286, 1537-1540.

Zhou, L., Kaufmann, R. K., Tian, Y., Myneni, R. B., \& Tucker, C. J. (2003). Relation between interannual variations in satellite measures of northern forest greenness and climate between 1982 and 1999. Journal of Geophysical Research, [Atmospheres], 108.

\section{Further reading}

Dia A., Van Schmus R., \& Kroner A. (1997). Isotopic constraints on the age and formation of a palaeoproterozoic volcanic arc complex in the Kedougou Inlier, Eastern Senegal, West Africa. Journal of African Earth Sciences, 24, 197-213.

Nemani R. R., Keeling C. D., Hashimoto H., Jolly W. M., Piper S. C., \& Tucker C. J., et al. (2003). Climate-driven increases in global terrestrial net primary production from 1982 to 1999. Science, 300, $1560-1563$. 